ISSN 0103-8478

\title{
Estabelecimento e crescimento in vitro de plantas de grápia
}

\author{
In vitro establishment and growth of apuleia seedlings
}

\author{
Kelen Haygert Lencina ${ }^{\mathrm{I}}$ Dilson Antônio Bisognin ${ }^{\mathrm{II}^{*}}$ Paula Kielse $^{\mathrm{II}}$ \\ Nathalia Pimentel ${ }^{\mathbb{I}}$ Frederico Dimas Fleig ${ }^{\mathrm{I}}$
}

\section{RESUMO}

O objetivo deste trabalho foi avaliar o estabelecimento e crescimento in vitro de plantas de grápia (Apuleia leiocarpa (Vogel) J. F. Macbr.) em diferentes condições de cultivo. Sementes de grápia tratadas com ácido sulfúrico $\left(\mathrm{H}_{2} \mathrm{SO}_{4}\right)$ por $20 \mathrm{~min}$ foram imersas em etanol a $70 \%$ por $30 \mathrm{~s}$ e em hipoclorito de sódio (0; 2,5 ou 5,0\% de cloro ativo) por 5, 10 ou 15min. Aos 30 dias de cultivo, as sementes foram avaliadas quanto às porcentagens de desinfestação e germinação. As plantas assépticas foram transferidas para os meios de cultura WPM, MS e $1 \frac{1}{2}$ MS e avaliadas quanto ao comprimento $(\mathrm{cm})$ da parte aérea e total das raízes e ao número de segmentos nodais e folhas aos 15 dias. Sementes de grápia também foram semeadas em meio de cultura WPM, suplementado com 4, 5 ou $6 \mathrm{~g} \mathrm{~L}^{-1}$ de agar combinado com 10, 20 ou $30 \mathrm{~g} \mathrm{~L}^{-1}$ de sacarose, e mantidos sob duas condições de luminosidade: luz durante todo o período de estabelecimento e escuro durante sete dias após a semeadura. Foram avaliados a porcentagem de germinação das sementes, o comprimento $(\mathrm{cm})$ da parte aérea e total das raízes e o número de segmentos nodais e folhas aos 15 dias. Concluiu-se que os tratamentos com ácido sulfúrico e etanol foram suficientes para o estabelecimento in vitro de plantas assépticas de grápia. Plantas assépticas podem ser cultivadas em meio de cultura WPM ou MS, suplementados com $10 g L^{-1}$ de sacarose e $4 g L^{-1}$ de agar.

Palavras-chave: Apuleia leiocarpa, desinfestação de sementes, germinação, meio de cultura, condição de cultivo.

\section{ABSTRACT}

The aim of this study was to evaluate the in vitro establishment and growth of apuleia (Apuleia leiocarpa (Vogel) J. F. Macbr.) seedlings under different culture conditions. Apuleia seeds were treated with sulfuric acid $\left(\mathrm{H}_{2} \mathrm{SO}_{4}\right)$ for $20 \mathrm{~min}$ and disinfected by the immersion in $70 \%$ of ethanol for 30s and sodium hypochlorite with $0,2.5$ and 5.0\% of active chlorine for 5, 10 and 15min. The percentage of disinfection and germination were evaluated at 30 days. Aseptic seedlings were transferred to WPM, MS and $1 / 2$ MS culture medium and evaluated for shoot and root (cm) growth and number of nodal segments and leaves at 15 days. Apuleia seeds were also sown in WPM medium supplemented with 4,5 or $6 \mathrm{~g} \mathrm{~L}^{-1}$ of agar combined with 10, 20 or $30 \mathrm{~g} \mathrm{~L}^{-1}$ of sucrose. The cultures were kept under two luminescence conditions: light throughout the establishment period and dark during the first seven days. The percentage of germination, shoot and root $(\mathrm{cm})$ growth and number of nodal segments and leaves were evaluated at 15 days. In conclusion, the sulfuric acid and ethanol treatments were enough for the in vitro production of apuleia aseptic seedlings. The aseptic seedlings can grow in both WPM and MS medium, supplemented with $10 \mathrm{~g} L^{-1}$ of sucrose and $4 g L^{-1}$ of agar.

Key words: Apuleia leiocarpa, seeds disinfection, germination, culture medium, growth conditions.

\section{INTRODUÇÃO}

A grápia (Apuleia leiocarpa (Vogel) J. F. Macbr. - Fabaceae), espécie arbórea nativa do Rio Grande do Sul, é considerada nobre pelas características da madeira e prioritária nas ações relativas à conservação in situ e in vitro, sobretudo por se tratar de uma espécie vulnerável a extinção (SEMA, 2006). Tendo em vista a redução das populações naturais de grápia, ações que envolvam a produção de mudas e o enriquecimento de áreas florestais são imprescindíveis para delinear estratégias que visem à conservação, ao manejo sustentado e ao melhoramento genético dessa espécie.

'Programa de Pós-graduação em Engenharia Florestal, Universidade Federal de Santa Maria (UFSM), Santa Maria, RS, Brasil.

IIDepartamento de Fitotecnia, UFSM, Av. Roraima, s/n, Camobi, 97105-900, Santa Maria, RS, Brasil. E-mail: dilson.bisognin@ufsm.br. ${ }^{*}$ Autor para correspondência. 
Com base na literatura, fica evidente a carência de estudos de propagação vegetativa de grápia para a produção de mudas em larga escala e de alta qualidade genética e fitossanitária, características que se constituem no ponto de partida para o estabelecimento de povoamentos comerciais uniformes e de alta produtividade. Os relatos existentes sobre a produção de mudas de grápia abordam, em sua maioria, a propagação por sementes. No entanto, as sementes dessa espécie apresentam tegumento resistente, exigindo tratamentos específicos de quebra de dormência para uniformizar o processo de germinação, o que restringe a produção massal de mudas. Além disso, a grápia possui frutificação irregular e as árvores atingem altura de até $35 \mathrm{~m}$, o que dificulta a coleta das sementes (CARVALHO, 2003).

$\mathrm{Na}$ micropropagação, o uso de métodos eficientes de desinfestação e germinação in vitro de sementes permite a obtenção de plantas assépticas fornecedoras de propágulos livre de contaminantes, os quais podem ser usados para a multiplicação e posterior enraizamento in vitro ou ex vitro (GRATTAPAGLIA \& MACHADO, 1998). Diversas substâncias têm sido utilizadas para a desinfestação de sementes de espécies arbóreas, entre as quais se destaca o hipoclorito (de sódio ou de cálcio), pela facilidade de remoção dos tecidos das sementes durante a lavagem com água, por favorecer a germinação em virtude da capacidade de estimular a atividade da $\alpha$-amilase e, ainda, pelo fato de promover o rompimento da dormência das sementes de algumas espécies (KANEKO \& MOROHASHI, 2003).

A composição do meio de cultura, a concentração de sacarose e agar e as condições de iluminação são fatores que também podem influenciar na germinação das sementes e no estabelecimento in vitro de plantas assépticas (ZHANG et al., 2003). A sacarose é essencial para o crescimento das plantas, pelo fato dos processos fotossintéticos realizados por plantas mantidas in vitro serem limitados. $\mathrm{O}$ agar é um polissacarídeo de alto peso molecular, sendo empregado na cultura de tecidos para dar sustentação aos explantes e às plantas mantidas in vitro. A concentração de agar no meio de cultura deve ser considerada, pois altos níveis dessa substância podem afetar a disponibilidade e a difusão dos demais componentes, além de atuar como osmorregulador (CID \& TEIXEIRA, 2010). Além dos componentes do meio de cultura, a luz, a temperatura e a disponibilidade de água são fatores desencadeadores e reguladores da germinação (BAI \& ROMO, 1995).

Apesar da identificação da condição ótima para a germinação de sementes e para o crescimento de plantas estabelecidas in vitro ser determinante para a obtenção de protocolos confiáveis de micropropagação, não há referências de estudos com essa abordagem para a grápia. Sendo assim, objetivou-se com este trabalho, avaliar a influência de diferentes tratamentos de desinfestação das sementes e condições de cultivo no estabelecimento e crescimento in vitro das plantas de grápia.

\section{MATERIAL E MÉTODOS}

Os experimentos foram conduzidos durante os meses de março a maio de 2012 no Núcleo de Melhoramento e Propagação Vegetativa de Plantas (MPVP), Departamento de Fitotecnia da Universidade Federal de Santa Maria, Santa Maria, RS. Os cultivos foram mantidos em sala de crescimento com temperatura de $25 \pm 2^{\circ} \mathrm{C}$ e fotoperíodo de $16 \mathrm{~h}$, sob intensidade luminosa de $14,3 \mu \mathrm{E} \mathrm{m}^{-2} \mathrm{~S}^{-1}$, fornecida por lâmpadas fluorescentes.

Para o estabelecimento in vitro, sementes de grápia foram tratadas com ácido sulfúrico $\left(\mathrm{H}_{2} \mathrm{SO}_{4}\right)$ concentrado $(95-98 \%)$ por $20 \mathrm{~min}$, visando à quebra da dormência tegumentar, e lavadas em água corrente por $5 \mathrm{~min}$ (NICOLOSO et al., 1997). Após, as sementes foram imersas em solução de etanol a $70 \%$ por 30 s, seguido da imersão em soluções de hipoclorito de sódio $(\mathrm{NaOCl})$ nas concentrações de 0 ; 2,5 ou $5,0 \%$ de cloro ativo, durante 5,10 ou $15 \mathrm{~min}$.

O experimento foi um fatorial $3 \times 3$ (concentrações de $\mathrm{NaOCl}$ e tempo de imersão), no delineamento inteiramente casualizado, com dez repetições de quatro sementes por parcela. Aos 30 dias, foram avaliadas as porcentagens de germinação e de sementes desinfestadas, ou seja, sem a presença de fungos ou bactérias. Para obtenção do tempo médio de germinação (TMG) (HARRINGTON, 1972) e do índice de velocidade de germinação (IVG) (MAGUIRE, 1962), o número de sementes germinadas foi obtido em intervalos de três dias, até 30 dias após a semeadura. O critério considerado para contabilizar a germinação foi a protrusão da radícula nas sementes.

Para avaliar o efeito do meio de cultura no crescimento in vitro, plantas assépticas de grápia foram transplantadas para tubos de ensaio contendo, aproximadamente, $7 \mathrm{~mL}$ de meio de cultura WPM (LLOYD \& MCCOWN, 1980), MS (MURASHIGE \& SKOOG, 1962) e 1/2 MS (MS com a concentração de sais minerais e vitaminas dividida pela metade), acrescidos 
de sacarose $\left(30 \mathrm{~g} \mathrm{~L}^{-1}\right)$ e agar $\left(7 \mathrm{~g} \mathrm{~L}^{-1}\right)$. O pH dos meios de cultura foi ajustado em 5,8 antes da autoclavagem. $\mathrm{O}$ delineamento utilizado foi o inteiramente casualizado, com dez repetições de quatro sementes por parcela. Aos 15 dias em sala de crescimento, as plantas foram avaliadas quanto ao comprimento da parte aérea $(\mathrm{cm})$, o comprimento total das raízes $(\mathrm{cm})$, e o número de segmentos nodais e folhas.

Para avaliar a influência da luminosidade e das concentrações de agar e sacarose, sementes de grápia foram submetidas aos tratamentos de ácido sulfúrico e etanol, conforme descrito anteriormente, e semeadas em meio de cultura WPM suplementado com 4,5 ou $6 \mathrm{~g} \mathrm{~L}^{-1}$ de agar combinado com 10, 20 ou 30 $\mathrm{g} \mathrm{L}^{-1}$ de sacarose. Os cultivos foram mantidos em sala de crescimento e submetidos a duas condições de luminosidade: luz durante toda a fase de estabelecimento e escuro durante os sete primeiros dias após a semeadura.

O experimento foi um fatorial $3 \times 3 \times 2$ (concentrações de agar, concentrações de sacarose e condição de luminosidade), no delineamento inteiramente casualizado, com cinco repetições de quatro sementes por parcela. Aos 15 dias, foi avaliada a porcentagem de germinação das sementes, o comprimento da parte aérea das plantas $(\mathrm{cm})$, o comprimento total das raízes $(\mathrm{cm})$ e o número de segmentos nodais. O número de sementes germinadas foi obtido em intervalos de três dias, até 30 dias após a semeadura, para o cálculo do TMG e IVG.

Para atender aos pressupostos da normalidade, os dados de porcentagem foram transformados para arcoseno $\sqrt{\mathrm{x}} / 100$ e submetidos à análise de variância. As médias dos tratamentos com diferenças significativas $(\mathrm{P}<0,05)$ foram comparadas pelo teste de Tukey ou regressão polinomial, com o auxílio do programa ESTAT (Unesp - Jaboticabal).

\section{RESULTADOS E DISCUSSÃO}

Para a porcentagem de sementes germinadas, não houve influência das concentrações de hipoclorito de sódio ( $\mathrm{NaOCl}$ ) e dos tempos de imersão, sendo observada média de $84,3 \%$ de germinação aos 30 dias de cultivo (Tabela 1). Neste estudo, também foi possível confirmar a eficiência da aplicação do $\mathrm{H}_{2} \mathrm{SO}_{4}$ na superação da dormência tegumentar de sementes de grápia, pois NICOLOSO et al. (1997) observaram $32,1 \%$ de germinação em sementes embebidas em água deionizada por $16 \mathrm{~h}$, não tratadas com $\mathrm{H}_{2} \mathrm{SO}_{4}$ e $100 \%$ de germinação em sementes de grápia tratadas com $\mathrm{H}_{2} \mathrm{SO}_{4}$, aos 5 dias de avaliação.

Tanto a concentração de $\mathrm{NaOCl}$ quanto o tempo de imersão não afetaram a porcentagem de sementes desinfestadas aos 30 dias de cultivo, sendo observados valores superiores a $92,5 \%$. Este resultado indica que o tratamento com $\mathrm{NaOCl}$ é desnecessário para a assepsia de sementes de grápia, quando há um tratamento prévio com ácido sulfúrico. É possível que o $\mathrm{H}_{2} \mathrm{SO}_{4}$ usado para a superação de dormência das sementes tenha atuado como agente desinfestante, o que pode explicar a baixa incidência de fungos e bactérias durante a fase de estabelecimento in vitro dessa espécie. Além disso, o etanol $70 \%$, usado na pré-assepsia do material, é considerado agente desinfestante (GRATTAPAGLIA \& MACHADO,

Tabela 1 - Porcentagem de germinação e desinfestação, tempo médio de germinação (TMG) e índice de velocidade de germinação (IVG) de sementes de grápia tratadas com diferentes concentrações e tempos de imersão em hipoclorito de sódio, aos 30 dias de avaliação. Santa Maria, RS, 2012.

\begin{tabular}{lcccc}
\hline Tempos de imersão (min) & Germinação (\%) & Desinfestação (\%) & TMG (dias) & IVG (dias) \\
\hline 5 & $95,1 \mathrm{a}^{*}$ & $92,5 \mathrm{a}$ & 6,5 & 6,9 \\
10 & $75,1 \mathrm{a}$ & $92,5 \mathrm{a}$ & 5,8 & 5,1 \\
15 & $81,4 \mathrm{a}$ & $97,5 \mathrm{a}$ & TMG (dias) & 6,3 \\
$\mathrm{NaOCl}$ ativo (\%) & $\% \mathrm{G}$ & $\% \mathrm{D}$ & 6,3 & IVG (dias) \\
0 (controle) & $86,4 \mathrm{a}$ & $97,5 \mathrm{a}$ & 6,9 & 6,0 \\
2,5 & $77,9 \mathrm{a}$ & $96,9 \mathrm{a}$ & 4,7 & 6,3 \\
5,0 & $89,7 \mathrm{a}$ & $93,1 \mathrm{a}$ & 6,8 & 6,4 \\
Média & 84,3 & 95,0 & - & - \\
CV (\%) & 36,9 & 14,9 & & 6 \\
\hline
\end{tabular}

* Valores seguidos de mesma letra não diferem entre si pelo teste de Tukey a 5\% de probabilidade de erro. 
1998) e, possivelmente, auxiliou no processo de desinfestação das sementes de grápia.

As sementes de grápia apresentaram TMG de 5,8 dias (Tabela 1). Sementes de louro-pardo (Cordia trichotoma Vell. Arrab. ex Steud.) semeadas in vitro apresentaram TMG de 13 dias no tratamento com água destilada durante 24 h (FICK et al., 2007). Em leucena (Leucaena leucocephala Wit.), os valores de TMG foram de 2,4 dias para sementes tratadas com ácido sulfúrico por 10min e de 5,8 dias para sementes imersas em água a $100^{\circ} \mathrm{C}$ (OLIVEIRA, 2008). Menores valores de TMG possibilitam maximizar a fase de estabelecimento de plantas para uso na micropropagação (MARTINS et al., 1999) e indicam alto vigor das sementes. Neste estudo, sementes tratadas com 5,0\% de $\mathrm{NaOCl}$ apresentaram maior vigor quando comparadas com as sementes tratadas com menor concentração de $\mathrm{NaOCl}(2,5 \%)$ ou não tratadas, ao se considerar o menor valor de TMG e o maior valor de IVG obtidos (Tabela 1). É possível que o vigor das sementes também seja influenciado pelo tempo de imersão em $\mathrm{NaOCl}$, o que foi detectado somente pelo TMG. O hipoclorito pode atuar como estimulante da germinação, em razão da capacidade de estimular a atividade da $\alpha$-amilase pelo aumento da quantidade dessa enzima na semente, ou ainda, pelo fato de promover a quebra da dormência das sementes de algumas espécies (KANEKO \& MOROHASHI, 2003). O TMG e o IVG têm grandezas inversamente proporcionais, à medida que, quanto menor o TMG e maior o IVG maior será o vigor das sementes. Cabe ressaltar que o lote de sementes de grápia utiliza neste estudo apresentou alto vigor de germinação, considerando os índices de TMG e IVG apresentados.

Não houve diferença significativa entre os meios de cultura WPM, MS e $1 / 2$ MS para o comprimento da parte aérea, número de folhas e comprimento da raiz de plantas de grápia (Tabela 2).
Para cerejeira (Amburana acreana (Ducke) A.C. Smith), espécie da mesma família botânica da grápia, a maior porcentagem de germinação das sementes $(86,7 \%)$ foi obtida em meio de cultura MS com a metade da concentração de sais (FERMINO JUNIOR \& SCHERWISNSKI-PEREIRA, 2012). Em plantas de Cordia trichotoma, foi verificado crescimento da parte aérea $(1,6 \mathrm{~cm})$ e daraiz $(7,3 \mathrm{~cm})$ significativamente superior nos cultivos em meio WPM, se comparados àqueles realizados em meio de cultura $1 / 2 \mathrm{MS}(0,7 \mathrm{e}$ $1,3 \mathrm{~cm}$ respectivamente), aos 28 dias de avaliação (FICK et al., 2007). Comparado ao meio de cultura MS, o meio WPM também se mostrou mais adequado para o estabelecimento in vitro de plantas de açoitacavalo (Luehea divaricata Mart. \& Zucc.), no qual foi observado maior número de nós por broto $(4,9)$ e maior enraizamento dos explantes $(66,8 \%)$, aos 60 dias de avaliação (FLÔRES, 2007). Para a grápia, o fato de não ter ocorrido diferença significativa entre os meios de cultura pode estar relacionado com o tempo de avaliação, que foi realizado aos 15 dias de cultivo, em razão de as plantas terem atingido a altura limite do tubo ensaio.

$\mathrm{Na}$ micropropagação, plantas que apresentam maior número de segmentos nodais ou gemas axilares são preferidas, ao se considerar que esses tipos de propágulos possuem menor variação somaclonal e epigenética (TORRES et al., 1999). Neste estudo, não houve diferença significativa entre os meios de cultura WPM, MS e 1/2 MS para o número de segmentos nodais (Tabela 2), indicando que o meio de cultura não influenciou o crescimento in vitro das plantas de grápia. Entretanto, o meio de cultura WPM foi utilizado para os demais experimentos por causa da sua formulação, que foi desenvolvida especialmente para espécies lenhosas e apresenta 25\% das concentrações de íons nitrato e amônia do meio MS (MELO et al., 1999), estimulando o

Tabela 2 - Comprimento da parte aérea, comprimento da raiz, número de segmentos nodais e folhas de plantas de grápia aos 15 dias de cultivo em três meios de cultura. Santa Maria, RS, 2012.

\begin{tabular}{lcccc}
\hline Tratamento & Comprimento da parte aérea $(\mathrm{cm})$ & Comprimento da raiz $(\mathrm{cm})$ & Número de segmentos nodais & Número de folhas \\
\hline WPM & $7,7 \mathrm{a}^{*}$ & $8,0 \mathrm{a}$ & $1,9 \mathrm{a}$ & $1,8 \mathrm{a}$ \\
MS & $7,4 \mathrm{a}$ & $7,0 \mathrm{a}$ & $1,7 \mathrm{a}$ & $4,5 \mathrm{a}$ \\
$1 / 2$ MS & $7,4 \mathrm{a}$ & $7,3 \mathrm{a}$ & 1,8 & $4,1 \mathrm{a}$ \\
Média & 7,5 & 7,4 & 7,6 & 4,3 \\
CV $(\%)$ & 4,4 & 9,3 & 6,3 & \\
\hline
\end{tabular}

* Valores seguidos de mesma letra não diferem entre si pelo teste de Tukey a 5\% de probabilidade de erro. 
crescimento in vitro pelas baixas concentrações de nitrogênio na forma amoniacal (GRATTAPAGLIA \& MACHADO, 1998). Além disso, o meio de cultura WPM possui maior quantidade da vitamina tiamina - $\mathrm{HCl}$, se comparado ao meio de cultura MS. A tiamina é apontada como uma substância benéfica para a multiplicação in vitro, possibilitando maior indução de brotos em explantes de espécies arbóreas (MANTOVANI \& FRANCO, 1998).

No estabelecimento in vitro das plantas, não houve interação significativa entre concentrações de agar e sacarose e a condição de luminosidade, para todas as variáveis analisadas. O comprimento da parte aérea das plantas foi afetado pela condição de luminosidade até os sete dias após a semeadura (Tabela 3 ). Sementes mantidas no escuro formaram plantas de maior comprimento, diferindo significativamente do tratamento formado por sementes expostas à luz.

A germinação de sementes de grápia ocorreu tanto na presença quanto na ausência de luz (Tabela 3), o que está de acordo com os resultados obtidos por HENICKA et al. (2006) ao avaliar a germinação de sementes da mesma espécie. No entanto, neste trabalho, foi observado que a manutenção das culturas no escuro durante os primeiros sete dias de estabelecimento in vitro diminuiu o tempo médio de germinação e aumentou a velocidade de germinação, ou seja, favoreceu o vigor das sementes. A luz tem ação na fotodegradação de compostos inibidores de crescimento presentes no tegumento das sementes, os quais podem ser substâncias de natureza fenólica, que retardam os processos metabólicos, prejudicando a germinação e o alongamento da parte aérea e do sistema radicular (MARTINOTTO et al., 2007). Além disso, a permanência das culturas no escuro resultou na formação de plantas com maior comprimento da parte aérea, possivelmente em decorrência do estiolamento, processo no qual a ausência de luz acarreta o alongamento de brotos, ramos ou outras partes da planta (HARTMANN \& KESTER, 2002). Para fins de micropropagação, o estiolamento aumenta os entre nós, o que facilita o preparo e a manipulação dos explantes (BARBOZA \& CALDAS, 2001).

Para grápia, o tratamento para a superação da dormência com $\mathrm{H}_{2} \mathrm{SO}_{4}$, associado à desinfestação das sementes com etanol $70 \%$, possibilitou a obtenção de grande número de plantas assépticas, as quais poderão ser utilizadas como fonte de explantes, permitindo o desenvolvimento de protocolos de micropropagação para essa espécie. O hipoclorito de sódio teve influência apenas no vigor das sementes, pois o aumento da sua concentração promoveu a redução do TMG e o aumento do IVG. As culturas foram mantidas no escuro nos primeiros sete dias para manter o vigor das sementes, o que favorece o estabelecimento in vitro das plantas e o crescimento da parte aérea. As plantas assépticas de grápia cresceram tanto em meio de cultura MS quanto em WPM, suplementados com $10 \mathrm{~g} \mathrm{~L}^{-1}$ de sacarose e $4 \mathrm{~g}$ $\mathrm{L}^{-1}$ de agar.

\section{CONCLUSÃO}

A quebra de dormência tegumentar e a préassepsia das sementes possibilitam o estabelecimento in vitro de plantas de grápia. Plantas assépticas de grápia podem ser cultivadas durante 15 dias em meio WPM ou MS, suplementados com $10 \mathrm{~g} \mathrm{~L}^{-1}$ de sacarose e $4 \mathrm{~g} \mathrm{~L}^{-1}$ de agar.

Tabela 3 - Comprimento da parte aérea, número de segmentos nodais, comprimento total das raízes, porcentagem de germinação, tempo médio de germinação (TMG) e índice de velocidade de germinação (IVG) de plantas de grápia aos 15 dias de avaliação. Santa Maria, RS, 2012.

\begin{tabular}{|c|c|c|c|c|c|c|}
\hline $\begin{array}{l}\text { Condição de } \\
\text { luminosidade }\end{array}$ & $\begin{array}{l}\text { Comprimento da } \\
\text { parte aérea }(\mathrm{cm})\end{array}$ & $\begin{array}{c}\text { № de segmentos } \\
\text { nodais }\end{array}$ & $\begin{array}{l}\text { Comprimento } \\
\text { das raízes }(\mathrm{cm})\end{array}$ & Germinação (\%) & TMG & IVG \\
\hline Escuro & $8,8 a^{*}$ & $1,8 \mathrm{a}$ & $8,7 \mathrm{a}$ & $92,6 \mathrm{a}$ & 3,6 & 15,1 \\
\hline Luz & $7,5 \mathrm{~b}$ & $1,6 \mathrm{a}$ & $7,5 \mathrm{a}$ & $85,1 \mathrm{a}$ & 5,0 & 11,2 \\
\hline Média & 8,15 & 1,7 & 8,1 & 88,8 & 4,3 & 13,1 \\
\hline CV $(\%)$ & 8,6 & 16,5 & 7,2 & 24,9 & - & - \\
\hline
\end{tabular}

* Valores seguidos de mesma letra não diferem entre si pelo teste de Tukey a 5\% de probabilidade de erro. 


\section{REFERÊNCIAS}

BAI, Y.; ROMO, J.T. Seedling emergence of Artemisia frigid in relation to hydration-dehydration cycles and seedbed characteristics. Journal of Arid Environments, v.30, p.57-65, 1995. Disponível em: <http://ac.els-cdn.com/S0140196395800387/1s2.0-S0140196395800387-main.pdf?_tid=4f9d9ca6d813-11e2-9234-00000a acb360\&acdnat $=1371559002$ eccb687a59b315289610b85c0d4d905e >. Acesso em: 11 mar. 2013. doi: S0140196395800387.

BARBOZA, S.B.S.C.; CALDAS, L.S. Estiolamento e regeneração na multiplicação in vitro do abacaxizeiro híbrido PE x SC-52. Pesquisa agropecuária brasileira, v.36, n.3, p.417-424, 2001. Disponível em: <http://www.scielo.br/pdf/pab/v36n3/4783.pdf>. Acesso em: 21 out. 2013. doi: ISSN 0100-204X.

CARVALHO, P.E.R. Espécies arbóreas brasileiras. Brasília: Embrapa Informação Tecnológica, 2003. V.1, 1039p.

CID. L.P.B.; TEIXEIRA. J.B. Cultura in vitro de plantas. Brasília, DF: Embrapa Informações Tecnológica, 2010. 303p.

FERMINO JUNIOR, P.C.P.; SCHERWISNSKI-PEREIRA, J.E. Germinação e propagação in vitro de cerejeira (Amburana acreana (Ducke) A.C. Smith - fabaceae). Ciência Florestal, v.22, n.1, p.1-9, 2012. Disponível em: <http://cascavel.ufsm.br/revistas/ ojs-2.2.2/index.php/cienciaflorestal/article/view/5074/3067>. Acesso em: 21 out. 2013. doi: ISSN 0103-9954.

FICK, T.A. et al. Estabelecimento e crescimento in vitro de plântulas de louro-pardo. Ciência Florestal, v.17, n.4, p.343-349, 2007. Disponível em: <http://www.bioline.org.br/pdf?cf07038>. Acesso em: 15 jan. 2013. doi: 0103-9954.

FLÔRES, A. Introdução ao cultivo in vitro de açoita-cavalo (Luehea divaricata Martius et Zuccarini). 2007. 73f. Dissertação (Mestrado em Engenharia Florestal) - Curso de Pós-graduação em Engenharia Florestal, Universidade Federal de Santa Maria, RS.

GRATTAPAGLiA, D.; MACHADO, M.A. Micropropagação. In: TORRES, A.C. et al. Cultura de tecidos e transformação genética de plantas. Brasília: EMBRAPA, 1998. V.1, p.183-260.

HARRINGTON, J.F. Seed storage and longevity. In: KOZLOWSKI, T.T. Seed biology. New York: Academic, 1972. p. $145-245$.

HARTMANN, H.T.; KESTER, D.E. Plant propagation: principles and practices. 7.ed. New Jersey: Prentice-Hall, 2002. 880 p.

HENICKA G. da S. et al. Germinação de sementes de Apuleia leiocarpa (VOGEL.) J. F. MACBR.: temperatura, fotoblastismo e estresse salino. Revista de Ciências AgroAmbientais, v.4, n.1, p.37-46, 2006. Disponível em: <http://www.unemat.br/revistas/ rcaa/docs/vol4/5_artigo_v4.pdf $>$. Acesso em: 22 jan. 2013.

KANEKO, K; MOROHASHI, Y. Effect of sodium hypochlorite treatment on the development of $\alpha$-amylase activity in mung bean cotyledons. Plant Science, v.164, p.287-292, 2003. Disponível em: <http://ac.els-cdn.com/S0168945202004119/1s2.0-S0168945202004119-main.pdf?_tid=5db89b64-d814-11e2- 8d0e-00000aab0f26\&acdnat $=1371559456 \_110 \mathrm{e} 36 \mathrm{e} 142 \mathrm{bd} 586$ 493917541c3890484>. Acesso em: 09 nov. 2012. doi: 01689452(02)00411-9.

LLOYD, G.; MCCOWN, B. Commercially-feasible micropropagation of mountain laure, Kalmia latifolia, by use of shoot-tip culture. International Plant Propagators Society Proceedings, v.30, p.421-427, 1980.

MAGUIRE, J.D. Speed of germination-aid in selection and evaluation for seedlig emergence and vigor. Crop Science, v.2, n.1, p.176-177, 1962.

MANTOVANI, N.C.; FRANCO, E.T.H. Cultura de tecidos de plantas lenhosas. Santa Maria: Centro de Pesquisas Florestais, UFSM, 1998. 132p. (Série técnica; v.12).

MARTINOTTO, C. Embriogênese somática e isolamento de protoplastos de pequizeiro. 2007. 106f. Tese (Doutorado em Agronomia) - Curso de Pós-graduação em Agronomia, Universidade Federal de Lavras, Lavras, MG.

MARTINS, C.C. et al. Efeito da posição da semente no substrato e no crescimento inicial das plântulas de palmito-vermelho (Euterpe espiritosantensis Fernandes - Palmae). Revista Brasileira de Sementes, v.21, n.1, p.164-173, 1999. Disponível em: <http:// www.abrates.org.br/revista/artigos/1999/v21n1/artigo25.pdf $>$. Acesso em: 10 mar. 2012.

MELO, N.F. de et al. Estabelecimento do cultivo in vitro de aceroleira (Malpighia emarginata DC). Ciência e Agrotecnologia, v.23, n.1, p-102-107, 1999. Disponível em: <http://www.cloud. editora.ufla.br/revista/cienagro/pdf/23/23-1-1999_14.pdf $>$. Acesso em: 13 fev. 2013.

MURASHIGE, T.; SKOOG, F. A revised medium for rapid growth and bioassay with tobacco tissue culture. Phisiology Plantarum, v.15, n.3, p.473-497, 1962.

NICOLOSO, F.T. et al. Efeito de métodos de escarificação na superação da dormência de sementes e dois substratos na germinação e no desenvolvimento da grápia (Apuleia leiocarpa). Ciência Rural, v.27, n.3, p.419-424, 1997. Disponível em: <http:// www.scielo.br/pdf/cr/v27n3/a09v27n3.pdf>. Acesso em: 11 mar. 2012. doi: 0103-8478/S0103-84781997000300009.

OLIVEIRA, A.B. de. Germinação de sementes de leucena (Leucaena leucocephala (Lam.) de Wit.), var. K-72. Revista de Biologia e Ciência da Terra, v.8, n.2, p.166-172, 2008. Disponível em: <http://eduep.uepb.edu.br/rbct/sumarios/pdf/18Leucena.pdf>. Acesso em: 11 mar. 2012. doi: ISSN 1519-5228.

SEMA. Árvore nativa: Biodiversidade também se planta. 2006. Disponível em: <http://www.sema.rs.gov.br/sema/jsp/descnoticias. jsp?ITEM=1270\&TIPO=1>. Acesso em: 21 out. 2012.

TORRES, A.C. et al. Cultura de tecidos e transformação genética de plantas. Brasília: EMBRAPA, 1999. V.2, 517p.

ZHANG, L. et al. Factors influencing shoots regeneration from cotyledons of tetraploid Isatis indigotica F. In vitro-Plant, v.39, p.459-462, 2003. Disponível em: <http://link.springer.com/ content/pdf/10.1079\%2FIVP2003447.pdf>. Acesso em: 10 mar. 2013. doi: 10.1079/IVP2003447. 